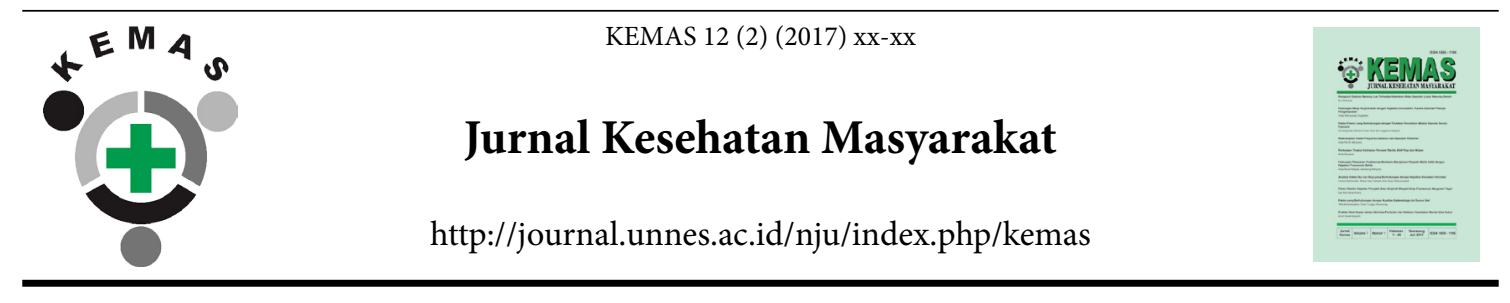

\title{
THE STUDY ON VALUE OF RECREATIONAL SPORTS ACTIVITY OF URBAN COMMUNITIES
}

\author{
Endang Sri Hanani ${ }^{凶}$ \\ Doctoral Program of Sports Education, Post Graduate Program, Universitas Negeri Semarang
}

\begin{tabular}{l} 
Article Info \\
\hline Article History: \\
Submitted 20 April 2016 \\
Accepted 5 September 2016 \\
Published Januari 2017 \\
\hline Keywords: \\
Recreational sports; \\
value; urban communities \\
\hline DOI \\
http://dx.doi.org/10.15294/ \\
kemas.v11i1.3521
\end{tabular}

Article Info

Accepted 5 September 2016

Published Januari 2017

kemas.v11i1.3521

\begin{abstract}
According to the WHO, health is not merely the absence of disease or infirmity, but a state of complete physical, mental, and social well-being. Recreational sports activities particularly for urban communities could be used as a life style, because it may considered balance individual condition between physical, spiritual and social needs. This study aims to describe and investigate: 1) the reason why recreational sports become urban society choice as weekend activities and holiday activities, 2) the type of recreational sport activities done by urban communities, 3) the value of individual's physical and psychosocial aspects,4) potential space for individual who do recreational sport activities. This research used ethnographic study with empirical and theoretical approaches. We conclude that the recreational sport activities as an option activity for the urban community, and is quite representative to facilitate the needs of sport cultures, and a sense of concern for the environment which useful in maintaining health.
\end{abstract}

\section{Introduction}

Recreation is a human right, thereby recreation can't be separated from every human life who never stop grow and develop. Whereas, growth and development of sport nowadays show many dimensions and may play important roles into intellectualization of nation, character building, moral education, and balancing between physical, spiritual and social needs. One of the sports that could actualize sport functions comprehensively is community recreational sports (Ann MacPhail, 2009).

The Law of Republic of Indonesia No. 3 year 2005 concerning the National Sports System, divide sport into three types: (1) sports for education, (2) sports for achievement, (3) sports for recreation. Recreational sports is important for the community, as a recreational sport may become a lifestyle, balancing between physical and spiritual needs, and improve physical, mental, and social well-being. Restoration of balance through recreational sport activities continue to develop into a recreational sport which is called "Sport for All" and may benefit to individual's physical, mental, and social well-being. According to the WHO, health is not merely the absence of disease or infirmity, but a state of complete physical, mental, and social well-being. Once human is free from all health problem, they should endure their body to improve their

\footnotetext{
Correspondece Address:

Program Studi Pendidikan Olahraga S3,

Program Pascasarjana, Universitas Negeri Semarang

Email : hanani_unnes@mail.unnes.ac.id
} 


\section{Introduction}

Recreation is a human right, thereby recreation can't be separated from every human life who never stop grow and develop. Whereas, growth and development of sport nowadays show many dimensions and may play important roles into intellectualization of nation, character building, moral education, and balancing between physical, spiritual and social needs. One of the sports that could actualize sport functions comprehensively is community recreational sports (Ann MacPhail, 2009).

The Law of Republic of Indonesia No. 3 year 2005 concerning the National Sports System, divide sport into three types: (1) sports for education, (2) sports for achievement, (3) sports for recreation. Recreational sports is important for the community, as a recreational sport may become a lifestyle, balancing between physical and spiritual needs, and improve physical, mental, and social well-being. Restoration of balance through recreational sport activities continue to develop into a recreational sport which is called "Sport for All" and may benefit to individual's physical, mental, and social well-being. According to the WHO, health is not merely the absence of disease or infirmity, but a state of complete physical, mental, and social well-being. Once human is free from all health problem, they should endure their body to improve their immune system, so they the disease can be prevented, one of many ways is doing sport (Kemenpora, 2011).

Various recreational sports activities on community may have various reason related to the issues such as motivation, purpose, behavior benefits (physically, mentally, socially), social values; potential space that safe, comfortable, and have likelihood to encourage individual for gaining physical, psychological and social values (Blazos, 2007). Most people that do sports activities are urban people which have broad spectrum of social status, economy status, education, and profession; however it doesn't put down their spirit doing recreational sports activities, since these activities have been doing as part to fulfill their needs (Ahmad, 2014) in expressing theirselves as a human who is visually need recognition from their surroundings.

Health status of individuals, groups or communities affected by four main factors: environment (physical, social, cultural, economic, political etc), behavior, healthcare, and heredity. Behavior as one of the determinants of health is someone responses to a stimulus. While, health behavior is person responses to the stimulus manifest as diseases, foods and beverages, environments and healthcare services. In public health practices such healthcare program (including environment and healthcare) are always in contact with the behavior matters (Novri, 2009). Individual behavior is affected by various issues such infectious and noninfectious diseases, environmental pollution, malnutrition, etc. For example, dengue fever occur cause people do not perform mosqoito control (3M), coronary heart disease due to unhealthy lifetstyle behavior, lack of exercise, and environmental pollution can cause a various health problems, as well as cause individual behavior that don't care about their environments.

Sports activities related to the values that can be apllied are include regular exercise habit, measurable, countable and monitorable, so will have health benefit (physical, mental, and social). Urban communities do recreational sports in their spare time is a reflection from the lifestyle of urban communities in order to fulfill their needs of health (physical, mental, social), as well as the to fulfill the needs of expression in controlling a behavior, as essential human recognition in the social life, dignified in the degree of personal health status and their environment. That's why the behavior can affect various problems in every corner of life (Boccaro, 2008).

The general objective of this study is to describe and investigate the value of sport recreation in urban communities and reason of recreational sport as choice of urban communities, whereas specifically, the purpose of this study are following: (1) describe and investigate the reasons of recreational sport activities as choice of urban communities as activities in spare time, (2) identify and assess forms of recreational sports activities performed in urban communities, (3) describe and assess the values that applied by the society 
as a result from the recreational sports activities (physical, mental and social), (4) identify and assess potential spaces that can be accessed in the urban community for recreational sports activities in their spare time.

Thus the recreational sports activities could provide an opportunity for individuals to implement a form of weekend activities, to obtain the value from the physical, psychological and social aspects from their surroundings. One of them is individuals can express theirselves as a human being whose have intrinsic value to meet the needs of self-actualization as a civilized human in their social life.

\section{Method}

This study used an ethnographic method with empirical and theoretical approach, units and subjects in this study were a group of gymnastic elderly, group of aerobics, groups of bikers, groups of walkers, and groups of joggers from urban communities, who do recreational sports activities at weekends and on holidays.

Location of the study corresponding to the issues and study objective took place in Semarang, precisely in the residential complex Graha Padma Semarang. We considered this location was very representative because: (1) Individuals who do recreational sports acitivity were a lot and diverse, participants ranging from children, adults, elderly, men and women either individually or in groups, (2) The open space that quite spacious and have adequate access as a green sport area, (3) the territory is free from conflict, secure, comfortable due to good security system.

According the issue and the study approach, the first step to obtain data is researcher positioned himself as data collector (human instrument) with physical examination method focused on testing individual fitness, observe participatory of events and selected forms of recreational sports chosen by subjects, in-depth interview about the value of individual psychosocial and document tracking to record information about the individual data.

The second step is validating data through data triangulation and informant triangulation by compared or confirmed the acquisition of similar data about the value of physical fitness, and the value of psychosocial from various sources or individuals recreational sports activity such as gymnastics elderly, aerobics, biking, walking, and jogging. The main data sources were descriptions that disclosed through (1) Event: the process of recreational sports activities of urban communities, (2) Actors: the urban communities who engaged in recreational sports activities, the participants of fitness test were consist of following groups: 25 people in gymnastics elderly, 15 people in aerobics, 13 people in biking, 10 people in walking, and 5 people in jogging, (3) Data source in the form of documented or written information of event implementation of recreational sports activities. Supportive data sources from sports experts, FORMI chairman of the Semarang city, and testimonial from sportsman

After that, the final step was analyzing the data, all the data and information obtained were analyzed wtih inductive approach using interactive cycle of Miles and Huberman, then data obtained was reduced, simplified, sorted, selected and sharphened from things that were not necessary.

\section{Result and Discussion}

The results showed the reason urban communities in urban areas chose recreational sport as an option activity on weekends and holidays, because indicidual were free to determined the forms, nature, space/area, groups, and communities, as spare time activity, especially at weekends and holidays, that was easy to do, inexpensive, fun and exciting. Recreational sports could be a lifestyle to maintain balance in the physical, mental and social aspcets, and may provide health benefits toward physical, mental, and social fitness.

Forms of recreation sports activities selected by individuals were gymnastics elderly (Gymnastics Tera Indonesia) exclusive for elderly men and women, aerobics exclusive for young mothers to pre-elderly, biking for men and women, children to adults, walking for male and female adolescents to elderly, and jogging for male and female adolescents and adults. Individuals could do this recreational sports activities in a groups and single, with the community, family, friends or colleagues, because in recreational sports activities there were values such psychological pleasure, the joy that radiates at their face, because expectation 
to stay healthy and always fit resonated to keep the spirit. For group aerobics and biking group impact was quite significant because the individuals were relatively young with ages below 50 years, so the physiological ability of the organ to be driven maximum workload was still capable, supported by three times a week activity, so the effect of these activities allowed the body (heart ) can be driven to work normally. For walking groups could also provide positive impact due to walking is activity that was suitable for every person, young or old, and the move is relative simple. The heart will work as the individuals capability. For jogging group, the individual were relatively on young age, so that the impact was very significant, this group consist of younger teenagers, teenagers, and adults, and they carried out 3 to 4 times per week and in around one hour duration, the rhythm was moderate. In this case, the heart can be stimulated optimally, so that the heart is able to work optimally without experiencing pain and fatigue, can recover quickly, including locomotor system with its muscles. For the walking group had a positive impact because walking is an activity that is in accordance with the conditions of the performers, and it can be done by any age (young or old). The heart work in accordance with their respective capabilities and movements of walking were relatively easy. The average fitness was in moderate and good category, with an average exercise four times a week. Optimalization of the heart could be more optimal.

Furthermore, results of the physical fitness test of each respective group were: gymnastics elderly group was $20 \%$ very low fitness, $40 \%$ low fitness, $40 \%$ moderate fitness category; aerobics group was $10 \%$ very low fitness, $20 \%$ low fitness, and $70 \%$ moderate fitness category. Whereas for biking group was $10 \%$ low fitness, $80 \%$ moderate fitness, $10 \%$ good fitness category; walking group was $50 \%$ moderate fitness, $50 \%$ good fitness its age group, and the last jogging group was 30\% low fitness and $70 \%$ moderate fitness.

Recreational sports activities can contribute to mental health, such as (1) more positive mindset (2) behavior control, in particular health behaviors such as no smoking behavior, exercise-related attitude such as obey the norm, diclipine behavior, keeping cleanness of environment, and respect each others. Recreational sports activity could made individual to be thinking clearly, have hopefull attitude toward what could do, including healthy behavior so will benefit and keeping their health, keep their existence as civilized creature. The description of mental health of recreational sports activityare including keeping community integrity and social control. This recreational sports role as interaction media, communication, integration of social interaction with their surroundings. As social human being, they must adapt to the surroundings, obey the norm, and community values, broadminded, avoid conflict and uphold social values in her daily behavior both towards others and the environment, passion and fun. (Ceria, 2006).

The social aspect of recreational sports showed that recreational sports acitivity could provide togetherness value, respect each others, tolerance to disparity, freedom to choose community, colleages, and comfortable enviroment, safe to express themselves that human whant to be recognized and respected as social creature which exist in their social life. Also has role as media to communicate with the surroundings, family, friends, and colleages which ease the access to broader interaction with the surroundings ( do not differentiate class, social status and financial status). Social aspects describe as keeping health behavior (physical, mental and social), community integration and social interaction into their surroundings. In recreational sports activity as groups, their presence can adapt to the surroundings, do not violate the norms or social values, avoid conflicts. (Cummings, 2006; Darla, 2007).

Potential space that could facilitate urban citizens to do recreational sports acitivity, such as wide open area, many selectable space, safe and comfort open space sports and green open space that adequately representative. This potential space provide more oxygen, sunlight, clean and green environments, therefore people will get motivated to do sports, also keep their mental and social existences. (Elizabeth, 2014; Fauzi, 2013).

Discussions that can be delivered based 
on the above results is that recereational sports is sport that is done by people with passion and skills grow and develop in accordance with the conditions and cultural values of local communities for health, fitness and excitement. Recreational sports performed as part of the recovery process health and fitness were done with no element of coercion and nuanced excitement. Besides, recreational sports aimed to building social relations among individuals and preserve and increase the wealth of national culture (FORMI, 2011).

Recreational sports is one sport that has significant importance in order to improve community health and fitness, but is also important in building national unity, peace and harmony, brotherhood and friendship, as well as improve the well-being, resilience and productivity of all people of Indonesia. Recreational sports can motivate a person to adopt healthy behaviors in daily life because in recreational sports there are elements that do not burden a person (reachable by everyone) in doing so because the activity of recreational sports activity as a pastime, especially at weekends and on holiday, simple, inexpensive, fun, and encouraging. Recreational sports can also be used as lifestyle to maintain balance in the physical, mental and social wellbeing. As well as a medium to communicate with the environment, family, friends, and colleages that facilitate in providing access to interact into the realm of social interaction to broader environment (not differentiate the class, status and position financially) so as to exchange opinions and ideas between each other, and give each other advice or fill in for others to live a healthy behavior in everyday life (Jacob, 2011).

Health behavior is a person's response to stimuli or objects associated with a healthy, pain, disease, and factors affecting the healthy, sick (health) such as the environment, food, beverage, and health services. In other words, health behavior is any activity or activities of someone either observable and unobservable relating to the maintenance and improvement of health (Natalie, 2014; Soegiyanto, 2010).

Health care was included to prevent and protect themselves from disease and other health problems, improve health, seek healing, when exposed to a health problem or illness. Health behaviors are divided into two, such as: (1) the behavior of healthy people to stay healthy, and (2) the behavior of people who are sick or developing health problems, to getting healthy. Healthy behaviors may be activities related with efforts to maintain and improve health, such as: (1) eat a balanced diet, (2) adequate physical activity or exercise, (3) no smoking, drinking, drugs, (4) adequate rest, (5) stress management, (6) and positive lifestyle (Kristin, 2013; Widowati, 2015).

So someone will make health care in himself when someone gets a stimulus, because a person's behavior is influenced by two main factors that form in a person, that is external factors such as stimulus from other people, external factors or stimulus in behavior is environment factors, both physical and nonphysical environment in the form of social, cultural, economic, political, and so forth. From the research that has been described above showed external factors wtih the greatest role in shaping individuals healthy behaviors is a social and cultural factors, where the person is located, cause relating to person in performing activities of recreational sports can give individual able to construct the perception that benefits of recreational sports activities is a trend of urban communities because it can control the behavior of health in the realm of social life in their surroundings (Novri, 2009; Joseph, 2004).

\section{Conclusion}

Based on the results and discussion above, it can be concluded that the impact of recreational sports activities on the value of fitness and health behaviors in use their spare time, can stimulate individuals in creating a healthy lifestyle, as well as reducing smoking behavior, for activities sport as a requirement in the development of health, consuming food intake that contain balanced nutrition, get adequate health care. The result of performers of gymnastics tera indicate their fitness is very low and low, because in this group almost all are elderly. Recreational sports activities when done to maintain fitness should begin with warming up, then core activities, and at last colling down. Recreational sports that done at weekends and holidays also acts as a media 
to construct behavior in maintaining health fitness, social interaction in their surroundings. Recreational sports for urban comunities, are free activity that can be done, with a sense of excitement, joy, without coercion, which can be used as an effort to control stress, health behaviors, maintan of physical, mental, and social fitness.

\section{Reference}

Ahmad Nasrulloh. 2014. Program Physical Fitness Dalam Meningkatkan Kesehatan Paru (Vo2 Max. Jurnal Kemas, 10 (1) : 1-6

Ann MacPhail, Connie Collier\&Mary O'Sullivan. 2009. Lifestyles and gendered patterns of leisure and sporting interests among Irish adolescents. Journal Sport, Education and Society. $4: 281-299$

Blazos, A.K., Grad D.D. \& Mark, L .W. 2007. Health Economics of Weight Management: Evidenceand Cost. Asia Pacific Journal of Clinical Nutrition, 16 (1) : 329-338

Boccaro, Kanters, Casper and Forrester. 2008. Sport Physical Education, Extracurricular Sports, and Lifelong Active Living. Journal of Teaching in Physical Education, 27 : 155-166.

Ceña, D.P. et al. 2006. Time Trends in Leisure Time Physical Activity and Physical Fitness in Elderly People: 20 Year Follow up of The Spanish Population National Health Survei (1987-2006). BMC Public Health, 22(6) : 223230

Cummings, Rick. 2006. What if: The Counterfactual in Evaluation Program. Evaluation Journal Australasia, 6: 6-15.

Darla M. Castelli et.al. 2007. Physical Fitness and Academic Achievement in Third- and Fifth-grade Students. Journal of Exercise and Psichology, 29 : 239-252.

Elisabeth Edvarsen, et.al. 2014. End Criteria for
Reaching Maximal Oxygen Uptake Must Be Strict and Adjusted to Sex and Age: A CrossSectional Study. Pos One, 9 (1) : 1-8.

Fauzi Lukman. 2013. Intensitas Jalan Kaki Terhadap Penurunan Kadar Glukosa Darah. Jurnal Kemas, 8(2) : 106-112.

FORMI. 2011. Makalah Seminar Olahraga Rekreasi Masyarakat. Semarang: Panitia Seminar.

Jacob, Steve and Yves Boisvert. 2011. To Be or Not to Be a Profession: Pros, Cons and Challenges for Evaluation. Journal Evaluation. 16 (4) : 349- 369.

Joseph P. Weir, et.al. 2004. $\mathrm{VO}_{2} \max$ Plateau Detection In Cycle Ergometry. Journal of exercise Physiology, 7 (2) : 55-62.

KEMENPORA. 2011. Panduan Umum Sentra Olahraga Rekreasi : Asisten Deputi Sentra Keolahragaan, Deputi Bidang Pembudayaan Olahraga. Jakarta: Kementrian Pemuda Dan Olahraga.

Kristin Walseth. 2013.Bridging and Bonding Social Capital in Sport-Experiences of Young Women with an Immigrant Background. Journal Sport, Education and Society, 13:1-17

Natalie L. Smith, Adam Cohen\&Andrew C. Pickett. 2014. Exploring the Motivations and Outcomes of Long-term International Sportfor-development Volunteering for American Millennials. Journal of Sport and Tourism. 19 : 299-316

Novri Susan. 2009. Sosiologi Konflik, Isu Isu Konflik kontemporer. Jakarta: Kencana Prenada Media Group.

Soegiyanto. KS. 2010. Aktivitas Jasmani Bagi Pekerja (Studi Kualitas Kesehatan Fisik Pada Buruh Pabrik). Jurnal Kemas. 6 (1) : 1-7.

Widowati, Atri. 2015. Modal Sosial Budaya dan Kondisi Lingkungan Sehat Dalam Pembinaan Prestasi Olahraga Pelajar. Jurnal Kemas. 10 (2) : 218-226. 